\title{
Optimizing Endocrine Therapy for Breast Cancer
}

\author{
Amelia B. Zelnak, MD, MSc, and Ruth M. O'Regan, MD
}

\begin{abstract}
Endocrine therapy has significantly improved outcomes for patients with early- and advanced-stage hormone-receptor (HR)positive breast cancer. Despite the success of adjuvant endocrine therapy, some patients with early-stage disease will experience relapse. Additionally, all patients with advanced disease will eventually experience disease progression on endocrine therapy due to resistance. Improved understanding of the mechanisms associated with resistance to endocrine agents has recently led to the approval of new therapeutics. Multiple questions remain unanswered, including the optimal duration of adjuvant therapy, the role of ovarian ablation in early-stage breast cancer in premenopausal women, and how to best incorporate targeted agents with endocrine therapy in the metastatic setting. This article reviews the optimization of endocrine therapy in patients with HR-positive breast cancer, focusing on these controversial areas. (J Natl Compr Canc Netw 2015;13:e56-e64)
\end{abstract}

Approximately two-thirds of breast cancers express either the estrogen receptor (ER), progesterone receptor (PR), or both, and this expression is predictive of benefit from endocrine therapies. ${ }^{1}$ The use of available endocrine agents has markedly improved outcomes for patients with all stages of hormone receptor (HR)-positive breast cancer. However, despite the marked success of endocrine therapy in the treatment of HR-positive breast cancers, many patients will experience relapse and all patients with advanced disease will ultimately experience disease progression, due to intrinsic or ac-

From the Department of Hematology and Medical Oncology, Winship Cancer Institute of Emory University and Georgia Cancer Center for Excellence, Grady Memorial Hospital, Atlanta, Georgia. Submitted May 8, 2014; accepted for publication December 3, 2014

Dr. Zelnak has disclosed that she is an advisor and board member for Pfizer. Dr. O'Regan has disclosed that she is an advisor for Genentech, AstraZeneca, and Pfizer.

Correspondence: Ruth M. O'Regan, MD, University of Wisconsin, 600 Highland Avenue, K4/542 CSC, Madison, WI 53792.

E-mail: roregan@medicine.wisc.edu quired resistance to endocrine therapy. The mechanisms underlying intrinsic and acquired resistance to endocrine agents are complex and likely similar, and include activation of growth factor pathways resulting in changes in coregulators of the ER. ${ }^{2-5}$

Molecular profiling has allowed a better understanding of the biology of HR-positive breast cancers. Analysis of these breast cancers using the intrinsic gene set has identified at least 2 distinct subtypes, luminal A and luminal $\mathrm{B}$, each of which has a unique biology and recurrence pattern. Luminal B cancers appear to harbor intrinsic resistance to endocrine therapy, which likely results in their high recurrence rate within the first 5 years of diagnosis. ${ }^{6}$ Other molecular assays, such as the 21 -gene recurrence score and the 70 -gene signature,, 8 provide prognostic information for patients with earlystage HR-positive breast cancers, and the use of the 21 gene recurrence score assay has allowed thousands of women with node-negative HR-positive breast cancer to avoid systemic chemotherapy, with all its inherent toxicities.

Despite the success with using targeted agents in HRpositive breast cancer, several critical questions remain. The use of molecular profiling has clearly allowed a more tailored approach to treating patients with early-stage HR-positive breast cancer, but has not been used to determine which patients truly benefit from endocrine therapy, or how long this treatment should be given. Whether a subset of premenopausal women with HR-positive early-stage breast cancer should receive ovarian ablation in combination with tamoxifen remains unclear. In the metastatic setting, although everolimus has been shown to improve outcome, the optimal timing at which to introduce mTOR inhibition remains unclear. This article reviews the optimization of endocrine therapy in patients with HR-positive breast cancer, with a specific focus on some of these controversial areas. 


\section{Early-Stage Breast Cancer}

\section{Premenopausal Women}

For patients who are premenopausal at the time of diagnosis of early-stage breast cancer, the current NCCN Clinical Practice Guidelines in Oncology (NCCN Guidelines) for Breast Cancer recommend that premenopausal women receive tamoxifen with or without ovarian suppression. ${ }^{9}$ The role of ovarian ablation via surgery, radiation, or suppression with luteinizing hormone-releasing hormone agonists has not been clearly defined. A meta-analysis of trials comparing ovarian ablation or suppression versus no adjuvant therapy showed improved outcomes; however, patients did not receive chemotherapy or tamoxifen. ${ }^{10}$ Other trials investigating the role of ovarian suppression in the adjuvant setting have yielded mixed results.

The Suppression of Ovarian Function Trial (SOFT; ClinicalTrials.gov identifier: NCT00066690) randomized women who were premenopausal and did not receive chemotherapy, or who remained premenopausal after completion of chemotherapy, to 5 years of either endocrine therapy with tamoxifen alone, tamoxifen plus ovarian suppression, or exemestane plus ovarian suppression. The Tamoxifen and Exemestane Trial (TEXT) compared tamoxifen plus ovarian suppression versus exemestane plus ovarian suppression. With a median follow-up of 68 months, a combined analysis of 4690 patients enrolled on SOFT and TEXT showed an improved 5-year disease-free survival (DFS) rate with exemestane plus ovarian suppression compared with tamoxifen plus ovarian suppression (91.1\% vs $87.3 \%$; hazard ratio [HR], 0.72; $P<.001) .{ }^{11}$ Results of the tamoxifen-alone arm from SOFT were not included in this analysis.

The Austrian Breast \& Colorectal Cancer Study Group trial 12 (ABCSG-12) was a smaller study of 1803 premenopausal women with HR-positive breast cancer randomized to either anastrozole plus ovarian suppression or tamoxifen plus ovarian suppression, with or without zoledronic acid. In contrast to the combined analysis of SOFT and TEXT, after a median follow-up period of 62 months, no significant difference in DFS was seen in ABCSG-12 (HR, 1.08; $P=.591) .{ }^{12}$ The differing results could be a result of the smaller study size in ABCSG-12. Based on the combined analysis of SOFT and TEXT, an aromatase inhibitor (AI) plus ovarian suppression represents a new option for patients. Multiple questions remain, such as the timing of ovarian suppression with chemotherapy (concurrently, as on TEXT vs sequentially, as on SOFT). For patients with chemotherapy-induced menopause, it is unknown whether similar benefit would be observed by switching from tamoxifen to an AI after postmenopausal status is confirmed, thereby eliminating the need for 5 years of ovarian suppression. Although the reported adverse events were similar between the 2 groups, subjects dropped out of the exemestane arm more frequently ( $16 \%$ vs $11 \%)$. The results of the tamoxifen-alone arm in SOFT are also anticipated to provide additional insight into the optimal management of early-stage HR-positive breast cancer in premenopausal patients.

\section{Postmenopausal Women}

In postmenopausal women, estrogen is synthesized when androgenic substrates produced by the adrenal glands are converted to estradiol by the aromatase enzyme. ${ }^{13}$ AIs suppress plasma estrogen levels in postmenopausal women. The ATAC trial (Arimidex, Tamoxifen, Alone or in Combination) was a landmark study of more than 9000 patients comparing 5 years of anastrozole with 5 years of tamoxifen, and showed improved DFS with anastrozole compared with tamoxifen. ${ }^{14}$ Similarly, the Breast International Group 1-98 (BIG 1-98) trial also showed improved DFS with 5 years of letrozole compared with 5 years of tamoxifen. ${ }^{15}$ Several trials have investigated the benefit of switching to an AI after tamoxifen for 2 to 3 years compared with completing 5 years of tamoxifen, showing improved DFS. ${ }^{16-19}$ Overall, all available trials demonstrate a benefit to using AIs as adjuvant therapy for HR-positive early-stage breast cancer in postmenopausal women, but whether an upfront AI is superior to tamoxifen for 2 to 5 years followed by an AI is unclear (Table 1). The Tamoxifen Exemestane Adjuvant Multinational (TEAM) trial compared 5 years of exemestane versus sequential therapy with tamoxifen followed by exemestane, and showed no significant difference in long-term outcome. ${ }^{20}$ The NCCN Guidelines recommend that postmenopausal patients receive an AI upfront for 5 years; or in sequence before or after 2 to 3 years of tamoxifen; or as extended adjuvant therapy after 5 years of tamoxifen. ${ }^{9}$ For women with a contraindication or intolerance to an AI, 5 years of tamoxifen, or consideration of up to 10 years, is recommended. ${ }^{9}$ 


\begin{tabular}{|c|c|c|c|c|c|}
\hline Trial & Drugs & $\begin{array}{l}\text { Number of } \\
\text { Subjects }\end{array}$ & $\begin{array}{l}\text { Median } \\
\text { Follow-up } \\
\text { (y) }\end{array}$ & $\begin{array}{l}\text { Disease-Free } \\
\text { Survival }\end{array}$ & $\begin{array}{l}\text { Hazard Ratio } \\
(95 \% \mathrm{Cl})^{\mathrm{a}}\end{array}$ \\
\hline ATAC $^{14}$ & $\begin{array}{l}\text { Anastrozole } \\
\text { Tamoxifen }\end{array}$ & $\begin{array}{l}3125 \\
3116\end{array}$ & 10 & $\begin{array}{l}69.5 \% \\
67.2 \%\end{array}$ & $\begin{array}{l}0.91(0.83-0.99) \\
P=.04\end{array}$ \\
\hline BIG 1-98 ${ }^{15}$ & $\begin{array}{l}\text { Letrozole } \\
\text { Tamoxifen } \\
\text { Letrozole } \rightarrow \text { Tamoxifen } \\
\text { Tamoxifen } \rightarrow \text { Letrozole }\end{array}$ & $\begin{array}{l}2463 \\
2459 \\
1540 \\
1548\end{array}$ & 8.1 & $\begin{array}{l}76.4 \% \\
72.0 \% \\
77.8 \% \\
77.3 \%\end{array}$ & $\begin{array}{l}0.82(0.74-0.92) \\
P=.0002^{\mathrm{a}}\end{array}$ \\
\hline $\mathrm{IES}^{17,19}$ & $\begin{array}{l}\text { Tamoxifen } \\
\text { Tamoxifen } \rightarrow \text { Exemestane }\end{array}$ & $\begin{array}{l}2305 \\
2294\end{array}$ & 7.6 & $\begin{array}{l}82.4 \% \\
84.7 \%\end{array}$ & $\begin{array}{l}0.81(0.71-0.92) \\
P=.001\end{array}$ \\
\hline ITA $^{16}$ & $\begin{array}{l}\text { Tamoxifen } \\
\text { Tamoxifen } \rightarrow \text { Anastrozole }\end{array}$ & $\begin{array}{l}225 \\
223\end{array}$ & 5.3 & $\begin{array}{l}72 \% \\
82.5 \%\end{array}$ & $\begin{array}{l}0.57(0.38-0.85) \\
P=.005\end{array}$ \\
\hline $\begin{array}{l}\text { ABCSG 8/ } \\
\text { ARNO } 95^{18}\end{array}$ & $\begin{array}{l}\text { Tamoxifen } \\
\text { Tamoxifen } \rightarrow \text { Anastrozole }\end{array}$ & $\begin{array}{l}1606 \\
1618\end{array}$ & 2.3 & $\begin{array}{l}93.2 \% \\
95.6 \%\end{array}$ & $\begin{array}{l}0.60(0.44-0.81) \\
P=.0009\end{array}$ \\
\hline TEAM $^{20}$ & $\begin{array}{l}\text { Exemestane } \\
\text { Tamoxifen } \rightarrow \text { Exemestane }\end{array}$ & $\begin{array}{l}4875 \\
4904\end{array}$ & 5.1 & $\begin{array}{l}86 \% \\
85 \%\end{array}$ & $\begin{array}{l}0.97(0.88-1.08) \\
P=.60\end{array}$ \\
\hline
\end{tabular}

Abbreviations: ABCSG, Austrian Breast \& Colorectal Cancer Study Group; ARNO, Arimidex-Nolvadex; ATAC, Arimidex, Tamoxifen, Alone or in Combination; BIG 1-98, Breast International Group 1-98; IES, Intergroup Exemestane Study; ITA, Italian Tamoxifen Anastrozole; TEAM, Tamoxifen Exemestane Adjuvant Multinational.

a Hazard ratio for letrozole versus tamoxifen arms.

\section{Duration of Endocrine Therapy}

Unlike other subtypes of breast cancer, late recurrences are a hallmark of a subset of HR-positive cancers. The recommendation to stop endocrine therapy at 5 years was based primarily on data from the NSABP (National Surgical Adjuvant Breast and Bowel Project) B-14 trial that demonstrated a higher recurrence rate in patients with nodenegative $\mathrm{HR}$-positive breast cancer who received 10 years, compared with 5 years, of tamoxifen. ${ }^{21}$ However, several trials have shown the benefit of extending adjuvant endocrine therapy to 10 years (Table 2). ${ }^{22,23}$ The National Cancer Institute of Canada (NCIC) MA.17 trial demonstrated a significant improvement in DFS in patients who received up to 5 years of letrozole after 5 years of tamoxifen, compared with placebo. ${ }^{24}$ The benefit of extended adjuvant therapy with letrozole was especially notable in patients with node-positive cancers and cancers that expressed both ER and PR. ${ }^{25}$ The Adjuvant Tamoxifen-To Offer More? (aTTom) and Adjuvant Tamoxifen: Longer Against Shorter (ATLAS) trials both compared 5 versus 10 years of tamoxifen. Both trials demonstrated reduced risk of recurrence and mortality with longer treatment. Among the almost 7000 subjects with ER-positive disease on the ATLAS trial, the risk of recurrence in years 5 to 14 was $21.4 \%$ in the group taking tamoxifen for 10 years compared with $25.1 \%$ in the control group. ${ }^{26} \mathrm{Sim}$ ilar improvements in long-term outcome were observed among nearly 7000 patients who received 10 years of tamoxifen on the aTTom trial. ${ }^{27}$ Interestingly, in the ATLAS and aTTOM trials, most of the benefit was seen after subjects completed 10 years of tamoxifen, most likely because of a carryover effect of the 5 years of tamoxifen. The risks for development of endometrial cancer and venous thromboembolic events were increased in the women who received 10 years of tamoxifen..$^{26,27}$ Both of these studies included premenopausal and postmenopausal patients. The different results seen in NSABP B-14 perhaps may be explained by the larger number of patients with higher-risk disease on the ATLAS and aTTom trials. No data are currently available regarding the use of adjuvant AIs beyond 5 years, and results of the NSABP B-42 trial, in which patients who have received either 5 years of an AI or tamoxifen for 2 years followed by an AI for 3 years, are awaited (ClinicalTrials.gov identifier: NCT00382070). A re-randomization of the MA.17 trial will evaluate durations of endocrine therapy longer than 10 years (ClinicalTrials. gov identifier: NCT00754845). 
Endocrine Therapy for Breast Cancer

\begin{tabular}{|c|c|c|c|c|c|}
\hline Trial & Duration of Therapy $(y)$ & $\begin{array}{l}\text { Number of } \\
\text { Subjects }\end{array}$ & $\begin{array}{l}\text { Median } \\
\text { Follow-up } \\
(y)^{\mathrm{a}}\end{array}$ & $\begin{array}{l}\text { Disease- } \\
\text { Free } \\
\text { Survival }\end{array}$ & $\begin{array}{l}\text { Hazard Ratio } \\
(95 \% \mathrm{Cl})\end{array}$ \\
\hline MA. $17^{24,25}$ & $\begin{array}{l}\text { Tamoxifen } \times 5 \\
\text { Tamoxifen } \times 5 \rightarrow \text { Letrozole } \times 5\end{array}$ & $\begin{array}{l}2582 \\
2575\end{array}$ & 2.4 & $\begin{array}{l}94.0 \% \\
96.4 \%\end{array}$ & $\begin{array}{l}0.58(0.45-0.76) \\
P=.00004\end{array}$ \\
\hline NSABP B-33 23 & $\begin{array}{l}\text { Tamoxifen } \times 5 \\
\text { Tamoxifen } \times 5 \rightarrow \text { Exemestane } \times 5\end{array}$ & $\begin{array}{l}779 \\
783\end{array}$ & 2.5 & $\begin{array}{l}88 \% \\
91 \%\end{array}$ & $\begin{array}{l}0.68 \\
P=.07\end{array}$ \\
\hline ABCSG $6 A^{22}$ & $\begin{array}{l}\text { Tamoxifen } \times 5 \\
\text { Tamoxifen } \times 5 \rightarrow \text { Anastrozole } \times 3\end{array}$ & $\begin{array}{l}469 \\
387\end{array}$ & 5.2 & $\begin{array}{l}88.2 \% \\
92.9 \%\end{array}$ & $\begin{array}{l}0.62(0.40-0.96) \\
P=.031\end{array}$ \\
\hline ATLAS $^{26}$ & $\begin{array}{l}\text { Tamoxifen x } 5 \\
\text { Tamoxifen x } 10\end{array}$ & $\begin{array}{l}3418 \\
3428\end{array}$ & 7.6 & $\begin{array}{l}74.9 \% \\
78.6 \%\end{array}$ & $P=.002$ \\
\hline aTTom ${ }^{27}$ & $\begin{array}{l}\text { Tamoxifen } \times 5 \\
\text { Tamoxifen } \times 10\end{array}$ & $\begin{array}{l}3485 \\
3468\end{array}$ & 10 & $\begin{array}{l}80.7 \% \\
83.3 \%\end{array}$ & $\begin{array}{l}0.85(0.76-0.95) \\
P=.003\end{array}$ \\
\hline
\end{tabular}

Abbreviations: ABCSG, Austrian Breast \& Colorectal Cancer Study Group; ATLAS, Adjuvant Tamoxifen: Longer Against Shorter; aTTom, Adjuvant Tamoxifen-To Offer More?; NSABP, National Surgical Adjuvant Breast and Bowel Project.

aMedian follow-up beyond initial 5 years of tamoxifen.

Although these trials all show an advantage to continuing endocrine therapy to 10 years, a critical issue is determining which patients need extended adjuvant therapy. Given the fact that luminal A cancers have a low rate of recurrence during the 5 years following diagnosis ${ }^{28}$ and seem to be sensitive to endocrine agents, one could hypothesize that this is the subset of breast cancers most likely to have late recurrences. However, at least up to 10 years after diagnosis, luminal B cancers continue to have a higher recurrence rate than luminal $\mathrm{A}$ cancers. ${ }^{29}$ The Breast Cancer Index (BCI), which includes the HOXB13:ILBR (H/I) gene expression ratio and the Molecular Grade Index, identifies 2 distinct subsets of ER-positive breast cancer with different rates of recurrence 5 to 10 years postdiagnosis. ${ }^{30}$ In multivariate analysis, BCI, which is now available in the United States, remained significant in predicting recurrences 5 to 10 years after diagnosis, whereas the 21-gene recurrence score and IHC4 assay, which is based on quantitative assessment of ER, PR, HER2, and Ki67, did not. ${ }^{30}$ The $\mathrm{H} / \mathrm{I}$ index has been demonstrated to be predictive of benefit from extended adjuvant AI therapy from a subset of the NCIC MA.17 trial. ${ }^{31}$ Other molecular assays, including the PAM50 riskof-recurrence score, which includes 46 genes from the intrinsic subset and tumor size, and the EndoPredict assay, have been shown to be predictive of recurrences beyond 5 years. ${ }^{32,33}$ Interestingly, looking at individual gene sets in the EndoPredict as- say, genes associated with proliferation seem to be predictive of recurrences within 5 years, whereas genes associated with ER signaling are predictive of later recurrences. ${ }^{33}$ Apart from BCI, none of these assays have been evaluated in trials in which patients received extended adjuvant therapy, and given that $\mathrm{BCI}$ was evaluated in a relatively small subset from the MA.17 trial, further validation would be appropriate before its widespread use to decide which patients need longer durations of endocrine therapy. Additionally, the ability of these assays to predict very late recurrences, which occur beyond 10 years, is currently unknown.

Taken together, it is reasonable to consider extended adjuvant therapy on an individual patient basis. If a patient remains premenopausal after completing 5 years of tamoxifen, one should consider extending tamoxifen treatment for an additional 5 years based on results of the ATLAS and aTTom trials. ${ }^{9}$ If a patient becomes definitively postmenopausal during the first 5 years of tamoxifen, switching to an AI for 5 additional years is a reasonable option, although this has not been compared with continuing tamoxifen for a total of 10 years. ${ }^{34}$ In postmenopausal women treated with upfront AIs or with tamoxifen followed by an AI, the long-term safety and efficacy of extending an AI beyond 5 years is not known and is currently under investigation. Until definitive data are available, extending therapy may be reasonable in patients with high-risk disease, particularly if they are tolerating treatment well. 


\section{Metastatic Breast Cancer}

\section{First-Line Therapy}

Before the development of third-generation AIs, tamoxifen was the standard of care for first-line treatment of HR-positive metastatic breast cancer (MBC). Based on the favorable toxicity profile of AIs and at least equivalent efficacy results compared with megestrol in patients whose disease had progressed on first-line tamoxifen, ${ }^{35-38}$ studies were initiated to evaluate AIs as first-line therapy for MBC. The largest trial randomized more than 900 patients with advanced breast cancer to either tamoxifen or letrozole. At a median follow-up of 32 months, letrozole was superior to tamoxifen, with a time to progression of 9.4 months versus 6 months for tamoxifen $(P<.0001){ }^{39,40}$ Similar trials comparing anastrozole and tamoxifen have also shown improved long-term outcomes with an AI in the first-line setting. ${ }^{41,42}$

Fulvestrant is a steroidal analogue of 17 -beta-estradiol and binds to the ER. This prevents receptor dimerization and downregulates ER. Fulvestrant is the only available agent in this class, and is administered as an intramuscular injection because of poor oral bioavailability. Fulvestrant was initially compared with anastrozole in patients with MBC who had progressed on first-line tamoxifen. These studies showed that fulvestrant was equivalent to anastrozole in time to progression, response rate, and clinical benefit rate. Based on these trials, fulvestrant was approved by the FDA for use in postmenopausal women with MBC who have progressed on previous hormonal therapy. ${ }^{43-45}$ Fulvestrant was subsequently compared with tamoxifen in the first-line setting, but showed equivalent outcome. ${ }^{46}$ Initial trials of fulvestrant used a monthly 250-mg injection; however, pharmacokinetic data showed that it could take 3 to 6 months to reach steady-state level. ${ }^{47}$ Subsequent trials were designed to evaluate alternative dosing schedules. Based on improved median progression-free survival (PFS) and median overall survival (OS) using a 500-mg loading dose on days 0,14 , and 28, the FDA updated the fulvestrant approval, recommending the 500-mg loading and therapeutic dose schedule, although this trial was not performed in the first-line setting. ${ }^{48}$ Fulvestrant at the higher dose schedule was demonstrated to be superior to anastrozole in the first-line treatment of HR-positive MBC, with median time to progression of 23 months compared with 13 months. ${ }^{49}$
The combination of fulvestrant and anastrozole in the first-line setting has also been compared with sequential therapy with anastrozole followed by fulvestrant in 2 trials with somewhat conflicting results. The SWOG trial showed improved median PFS in the combination arm compared with the sequential arm (13.5 vs 15.0 months; HR, 0.80; $P=.007) .{ }^{50} \mathrm{In}$ contrast, the Fulvestrant and Anastrozole Combination Therapy (FACT) trial did not show a significant improvement in median time to progression with the combination ( 10.8 vs 10.2 months; $P=.99) .{ }^{51}$ The conflicting results in these 2 trials may be attributed to differences in size of the trials and differences in patient populations, with the SWOG trial having more patients with de novo MBC. Median PFS was longer in the anastrozole-only arm of the SWOG trial, compared with the FACT trial, suggesting that a higher proportion of patients in the SWOG trial had endocrine-sensitive disease.

The addition of targeted agents to first-line endocrine therapy is currently being evaluated. Palbociclib is an oral inhibitor of cyclin-dependent kinase 4 and 6 (CDK4/6), which are proteins involved in regulating cell cycle progression. ${ }^{52}$ Overexpression of cyclin D1 has been observed in more than one-third of breast cancers..$^{53}$ Cyclin D1 activates CDK4 and its continued activity plays a key role in maintaining breast tumorigenesis. ${ }^{54}$ Preclinical data showed activity of palbociclib in HR-positive breast cancer cells. ${ }^{55}$ PALOMA-1 was a randomized phase II trial that randomized 165 patients to either letrozole alone or combination palbociclib and letrozole as first-line therapy for HR-positive advanced breast cancer. Median PFS was 20.2 months in the combination arm compared with 10.2 months in the letrozole arm (HR, 0.49; $P=.0004) .{ }^{56}$ Based on these promising results, a phase III randomized trial is currently underway (ClinicalTrials.gov identifier: NCT01740427).

Preclinical data have supported a role of the ERSrc axis in the development of resistance to endocrine therapy. ${ }^{57}$ The addition of dasatinib, a Src tyrosine kinase inhibitor, to letrozole as first-line treatment for HR-positive MBC improved PFS from 10 to 20 months in a randomized phase II trial. ${ }^{58}$

In the absence of a clinical trial, decisions on optimal first-line endocrine therapy for patients with HR-positive disease should be made based on prior therapy in the adjuvant setting. The combination of fulvestrant and anastrozole is reasonable but should 
probably be reserved for patients with de novo MBC, or those who have a long disease-free interval from initial diagnosis.

\section{Prior Treatment With Nonsteroidal Als}

In the EFECT trial, patients with HR-positive MBC who had received prior therapy with a nonsteroidal AI were randomized to either exemestane or fulvestrant (Table 3). Time to progression was identical at just under 4 months in each arm, and no significant difference was seen in any of the other trial end points. ${ }^{59}$ This trial suggests that no single endocrine agent is superior to another in this setting. Additionally, the time to progression of less than 6 months suggests that most of the patients, all of whom had received at least a nonsteroidal AI previously, had endocrine-resistant disease. The EFECT trial has been used subsequently to design trials evaluating the addition of other targeted agents to endocrine therapy in patients with $\mathrm{HR}$-positive $\mathrm{MBC}$ who were previously treated with nonsteroidal AIs.

Endocrine resistance is a critical issue for patients with HR-positive MBC. Some tumors harbor intrinsic resistance to endocrine agents and do not benefit from endocrine therapy; in the metastatic setting, all tumors ultimately acquire resistance to endocrine therapy. The mechanisms underlying resistance to endocrine therapy are complex. However, enhanced signaling through growth factor receptor pathways has been demonstrated in preclinical and clinical studies. Activation of the PI3K/Akt/mTOR pathway can lead to estrogen-independent activation of ER and has been associated with resistance to endocrine therapy. ${ }^{60,61}$ Preclinical data showed that mTOR inhibition can restore sensitivity to endocrine therapy and induce apoptosis in breast cancer cells. ${ }^{62,63}$

BOLERO-2 was a randomized phase III trial evaluating the addition of the mTOR inhibitor everolimus to exemestane in patients with $\mathrm{MBC}$ whose disease had progressed or recurred after treatment with a nonsteroidal AI. The addition of everolimus to exemestane led to significant improvements in PFS (6.9 vs 2.8 months by local assessment, $P<.001 ; 10.6$ vs 4.1 months by central assessment, $P<.001)$. Recent OS data showed a nonsignificant improvement in OS from 26.6 months with exemestane alone to 31 months with exemestane plus everolimus (HR, 0.89; $P=.1426) .{ }^{64}$ However, the addition of everolimus was associated with increased toxicities. ${ }^{65}$ The most common grade 3 or 4 adverse events were stomatitis, fatigue, hyperglycemia, anemia, and pneumonitis. ${ }^{66}$ Based on the results of $\mathrm{BO}$ LERO-2, the FDA approved everolimus in combination with exemestane for postmenopausal patients with advanced breast cancer. Everolimus has been studied in combination with other endocrine agents. The TAMRAD trial was a phase II trial that compared combination tamoxifen and everolimus with tamoxifen alone. The clinical benefit rate was significantly improved in the combination arm $(61 \%$ vs $42 \% ; P=.045$ ), as was the time to progression (8.6 vs 4.5 months). The toxicities observed in TAMRAD were similar to those seen in BOLERO-2. ${ }^{67} \mathrm{~A}$ single-

\begin{tabular}{|c|c|c|c|c|}
\hline Trial & Drugs & $\begin{array}{l}\text { Number of } \\
\text { Subjects }\end{array}$ & $\begin{array}{l}\text { Progression- } \\
\text { Free Survival } \\
\text { (mo) }\end{array}$ & $\begin{array}{l}\text { Hazard Ratio } \\
(95 \% \mathrm{Cl})\end{array}$ \\
\hline EFECT $^{59}$ & $\begin{array}{l}\text { Exemestane } \\
\text { Fulvestrant }\end{array}$ & $\begin{array}{l}342 \\
351\end{array}$ & $\begin{array}{l}3.7 \\
3.7\end{array}$ & $\begin{array}{l}0.963(0.82-1.13) \\
P=.6531\end{array}$ \\
\hline BOLERO- $2^{64}$ & $\begin{array}{l}\text { Exemestane } \\
\text { Exemestane + everolimus }\end{array}$ & $\begin{array}{l}239 \\
485\end{array}$ & $\begin{array}{c}4.1^{\mathrm{a}} \\
10.6\end{array}$ & $\begin{array}{l}0.36(0.27-0.47) \\
P<.001\end{array}$ \\
\hline TAMRAD ${ }^{67}$ & $\begin{array}{l}\text { Tamoxifen } \\
\text { Tamoxifen + everolimus }\end{array}$ & $\begin{array}{l}57 \\
54\end{array}$ & $\begin{array}{l}4.5 \\
8.6\end{array}$ & $\begin{array}{l}0.54(0.36-0.81) \\
P=.0021\end{array}$ \\
\hline ENCORE $^{70}$ & $\begin{array}{l}\text { Exemestane } \\
\text { Exemestane + entinostat }\end{array}$ & $\begin{array}{l}66 \\
64\end{array}$ & $\begin{array}{l}2.3 \\
4.3\end{array}$ & $\begin{array}{l}0.73(0.50-1.07) \\
P=.055\end{array}$ \\
\hline
\end{tabular}

Abbreviations: BOLERO, Breast Cancer Trials of Oral Everolimus; EFECT, Evaluation of Faslodex versus Exemestane Trial; ENCORE, Entinostat Combinations Overcoming Resistance; TAMRAD, Tamoxifen Plus Everolimus.

aProgression-free survival reported according to central assessment. 
arm phase II trial of fulvestrant and everolimus in postmenopausal women who experienced disease progression or relapse on a nonsteroidal AI showed a median time to progression of 7.4 months and a clinical benefit rate of $49 \% .^{68}$

Preclinical data support the concept that histone deacetylase (HDAC) inhibitors may play a role in reversing resistance to endocrine therapy. ${ }^{69}$ The Entinostat Combination Overcoming Resistance (ENCORE) trial evaluated the addition of entinostat, a HDAC inhibitor, to exemestane in patients with HR-positive MBC who experienced prior disease progression on nonsteroidal AIs. Although no significant improvement was seen in PFS, a significant improvement in OS was noted. ${ }^{70}$ The FDA has designated entinostat as a Breakthrough Therapy, and results of the ENCORE trial will be confirmed in the ongoing ECOG 2112 trial.

At the time of disease progression on exemestane and everolimus, whether the cancer has developed resistance to the endocrine agent, everolimus, or both is unclear. Studies are underway to evaluate the potential benefit of continuing everolimus beyond progression with an alternative endocrine agent. Inhibition of PI3K signaling upstream of mTOR is currently being evaluated among patients who experience disease progression on everolimus. BELLE-3 (ClinicalTrials.gov identifier: NCT01633060) is an ongoing phase III trial randomizing patients to either fulvestrant or combination fulvestrant and BKM120 , an oral pan-class PI3K inhibitor. The addition of everolimus to adjuvant endocrine therapy is also being evaluated in patients with high-risk HR-positive breast cancer. A phase III trial comparing endocrine therapy alone versus endocrine therapy plus 1 year of everolimus is being conducted among patients with 4 or more positive axillary lymph nodes or a 21 -gene recurrence score greater than 25 .

Although everolimus is approved for patients with $\mathrm{HR}$-positive $\mathrm{MBC}$ who have received prior nonsteroidal AIs in the adjuvant or metastatic setting, given available preclinical data it seems likely that mTOR inhibition may be more effective in the endocrine-resistant setting. This hypothesis is supported by the fact that the addition of temsirolimus to letrozole did not improve outcomes in the firstline setting. ${ }^{71}$ Unfortunately there is no definitive way of determining whether a patient with $\mathrm{MBC}$ has endocrine-sensitive or endocrine-resistant disease without assessing the benefit of endocrine therapy in the metastatic setting. Given the additional toxicity of everolimus, it will be important to determine which line of therapy is optimal in patients with HRpositive metastatic disease.

\section{Conclusions and Future Directions}

The standard of care for adjuvant endocrine therapy for early-stage HR-positive breast cancer has evolved in recent years with the use of AIs in addition to tamoxifen for postmenopausal women. Although all postmenopausal women without a contraindication should be recommended to take an AI during adjuvant therapy, both the upfront $\mathrm{AI}$ use and sequential approach after tamoxifen are reasonable options. Several studies have shown benefit for extending adjuvant hormonal therapy to 10 years. Currently, no evidence supports extending therapy with an AI beyond 5 years, but the results of NSABP B-42 (ClinicalTrials.gov identifier: NCT00382070) addressing this question are eagerly anticipated. Molecular profiling should help define which patients require longer durations of adjuvant endocrine therapy.

Intrinsic resistance and the development of acquired resistance remain a significant challenge in the management of patients with HR-positive MBC. An improved understanding of the mechanisms of resistance to endocrine therapy has led to the development and approval of targeted therapies, such as everolimus in combination with endocrine therapy for patients with advanced breast cancer. Agents that target multiple growth factor receptors and signaling cascades are currently being developed with the goal of improving long-term outcomes.

Agents with proven efficacy in the metastatic setting should be considered for evaluation in patients with early-stage HR-positive breast cancer. Studies investigating the addition of everolimus to adjuvant endocrine therapy are currently ongoing. Because the addition of targeted agents to endocrine therapy is likely to increase toxicity, determining which patients are at higher risk for recurrence and most likely to benefit will be critical to improving long-term outcomes for early-stage HR-positive breast cancer. 
Endocrine Therapy for Breast Cancer

\section{References}

1. Anderson WF, Chatterjee N, Ershler WB, Brawley OW. Estrogen receptor breast cancer phenotypes in the Surveillance, Epidemiology, and End Results database. Breast Cancer Res Treat 2002;76:27-36.

2. De Laurentiis M, Arpino G, Massarelli E, et al. A meta-analysis on the interaction between HER-2 expression and response to endocrine treatment in advanced breast cancer. Clin Cancer Res 2005;11:4741-4748.

3. Cristofanilli M, Valero V, Mangalik A, et al. Phase II, randomized trial to compare anastrozole combined with gefitinib or placebo in postmenopausal women with hormone receptor-positive metastatic breast cancer. Clin Cancer Res 2010;16:1904-1914.

4. Traina TA, Rugo HS, Caravelli JF, et al. Feasibility trial of letrozole in combination with bevacizumab in patients with metastatic breast cancer. J Clin Oncol 2010;28:628-633.

5. Kaklamani VG, Cianfrocca M, Ciccone J, et al. Increased HER2/ neu expression in recurrent hormone receptor-positive breast cancer. Biomarkers 2010;15:191-193.

6. Sorlie T, Perou CM, Tibshirani R, et al. Gene expression patterns of breast carcinomas distinguish tumor subclasses with clinical implications. Proc Natl Acad Sci U S A 2001;98:10869-10874.

7. Paik $S$, Shak $S$, Tang $G$, et al. A multigene assay to predict recurrence of tamoxifen-treated, node-negative breast cancer. $\mathrm{N}$ Engl J Med 2004;351:2817-2826.

8. van 't Veer LJ, Dai H, van de Vijver MJ, et al. Gene expression profiling predicts clinical outcome of breast cancer. Nature 2002;415:530-536.

9. Gradishar WJ, Anderson BO, Balassanian R, et al. NCCN Clinical Practice Guidelines in Oncology: Breast Cancer. Version 2, 2015. Available at: NCCN.org. Accessed July 2, 2015.

10. Puhalla S, Brufsky A, Davidson N. Adjuvant endocrine therapy for premenopausal women with breast cancer. Breast 2009;18(Suppl 3):S122_ 130.

11. Pagani $O$, Regan MM, Walley BA, et al. Adjuvant exemestane with ovarian suppression in premenopausal breast cancer. $\mathrm{N}$ Engl J Med 2014;371:107-118.

12. Gnant M, Mlineritsch B, Stoeger $H$, et al. Adjuvant endocrine therapy plus zoledronic acid in premenopausal women with early-stage breast cancer: 62-month follow-up from the ABCSG-12 randomised trial. Lancet Oncol 2011;12:631-641.

13. Santen RJ, Harvey HA. Use of aromatase inhibitors in breast carcinoma Endocr Relat Cancer 1999;6:75-92.

14. Forbes JF, Cuzick J, Buzdar A, et al. Effect of anastrozole and tamoxifen as adjuvant treatment for early-stage breast cancer: 100-month analysis of the ATAC trial. Lancet Oncol 2008;9:45-53.

15. Regan MM, Neven P, Giobbie-Hurder A, et al. Assessment of letrozole and tamoxifen alone and in sequence for postmenopausal women with steroid hormone receptor-positive breast cancer: the BIG 1-98 randomised clinical trial at 8.1 years median follow-up. Lancet Oncol 2011;12:1101-1108.

16. Boccardo F, Rubagotti A, Guglielmini $P$, et al. Switching to anastrozole versus continued tamoxifen treatment of early breast cancer. Updated results of the Italian tamoxifen anastrozole (ITA) trial. Ann Oncol 2006;17(Suppl 7):vii10-14.

17. Coombes RC, Hall E, Gibson LJ, et al. A randomized trial of exemestane after two to three years of tamoxifen therapy in postmenopausal women with primary breast cancer. N Engl J Med 2004;350:1081-1092.

18. Jakesz R, Jonat W, Gnant M, et al. Switching of postmenopausal women with endocrine-responsive early breast cancer to anastrozole after 2 years' adjuvant tamoxifen: combined results of ABCSG trial 8 and ARNO 95 trial. Lancet 2005;366:455-462.

19. Bliss JM, Kilburn LS, Coleman RE, et al. Disease-related outcomes with long-term follow-up: an updated analysis of the intergroup exemestane study. J Clin Oncol 2012;30:709-717.

20. van de Velde CJ, Rea D, Seynaeve C, et al. Adjuvant tamoxifen and exemestane in early breast cancer (TEAM): a randomised phase 3 trial. Lancet 2011;377:321-331.

21. Fisher B, Dignam J, Bryant J, Wolmark N. Five versus more than five years of tamoxifen for lymph node-negative breast cancer: updated findings from the National Surgical Adjuvant Breast and Bowel Project B-14 randomized trial. J Natl Cancer Inst 2001;93:684-690.

22. Jakesz R, Greil R, Gnant M, et al. Extended adjuvant therapy with anastrozole among postmenopausal breast cancer patients: results from the randomized Austrian Breast and Colorectal Cancer Study Group Trial 6a. J Natl Cancer Inst 2007;99:1845-1853.
23. Mamounas EP, Jeong JH, Wickerham DL, et al. Benefit from exemestane as extended adjuvant therapy after 5 years of adjuvant tamoxifen: intentionto-treat analysis of the National Surgical Adjuvant Breast And Bowel Project B-33 trial. J Clin Oncol 2008;26:1965-1971.

24. Goss $\mathrm{PE}$, Ingle JN, Martino $\mathrm{S}$, et al. A randomized trial of letrozole in postmenopausal women after five years of tamoxifen therapy for early-stage breast cancer. N Engl J Med 2003;349:1793-1802.

25. Goss PE, Ingle JN, Martino S, et al. Efficacy of letrozole extended adjuvant therapy according to estrogen receptor and progesterone receptor status of the primary tumor: National Cancer Institute of Canada Clinical Trials Group MA.17. J Clin Oncol 2007;25:2006-2011.

26. Davies C, Pan H, Godwin J, et al. Long-term effects of continuing adjuvant tamoxifen to 10 years versus stopping at 5 years after diagnosis of oestrogen receptor-positive breast cancer: ATLAS, a randomised trial. Lancet 2013;381:805-816

27. Gray R, Rea D, Handley K, et al. aTTom: long-term effects of continuing adjuvant tamoxifen to 10 years versus stopping at 5 years in 6,953 women with early breast cancer [abstract]. J Clin Oncol 2013;31(Suppl):Abstract 5 .

28. Sorlie T, Tibshirani R, Parker J, et al. Repeated observation of breast tumor subtypes in independent gene expression data sets. Proc Natl Acad Sci U S A. 2003;100:8418-8423.

29. Sestak I, Cuzick J, Dowsett M, et al. Prediction of late distant recurrence after 5 years of endocrine treatment: a combined analysis of 2485 patients from the ABCSG-8 and transATAC studies using the PAM50 risk of recurrence (ROR) score [abstract]. Cancer Res 2013;73(Suppl):Abstract S6-04.

30. Sgroi DC, Sestak I, Cuzick J, et al. Prediction of late distant recurrence in patients with oestrogen-receptor-positive breast cancer: a prospective comparison of the breast-cancer index $(\mathrm{BCI})$ assay, 21-gene recurrence score, and IHC4 in the TransATAC study population. Lancet Oncol 2013;14:1067-1076.

31. Sgroi DC, Carney E, Zarrella E, et al. Prediction of late disease recurrence and extended adjuvant letrozole benefit by the HOXB13/IL17BR biomarker. J Natl Cancer Inst 2013;105:1036-1042.

32. Filipits M, Nielsen TO, Rudas M, et al. The PAM50 risk-of-recurrence score predicts risk for late distant recurrence after endocrine therapy in postmenopausal women with endocrine-responsive early breast cancer. Clin Cancer Res 2014;20:1298-1305.

33. Dubsky P, Brase JC, Jakesz R, et al. The EndoPredict score provides prognostic information on late distant metastases in ER+/HER2- breast cancer patients. Br J Cancer 2013;109:2959-2964.

34. Jin $\mathrm{H}, \mathrm{Tu} \mathrm{D}$, Zhao $\mathrm{N}$, et al. Longer-term outcomes of letrozole versus placebo after 5 years of tamoxifen in the NCIC CTG MA.17 trial: analyses adjusting for treatment crossover. J Clin Oncol 2012;30:718-721.

35. Buzdar A, Douma J, Davidson N, et al. Phase III, multicenter, doubleblind, randomized study of letrozole, an aromatase inhibitor, for advanced breast cancer versus megestrol acetate. J Clin Oncol 2001;19:3357-3366.

36. Buzdar AU, Jonat W, Howell A, et al. Anastrozole versus megestrol acetate in the treatment of postmenopausal women with advanced breast carcinoma: results of a survival update based on a combined analysis of data from two mature phase III trials. Arimidex Study Group. Cancer 1998;83:1142-1152.

37. Kaufmann M, Bajetta E, Dirix LY, et al. Exemestane is superior to megestrol acetate after tamoxifen failure in postmenopausal women with advanced breast cancer: results of a phase III randomized double-blind trial. The Exemestane Study Group. J Clin Oncol2000;18:1399-1411.

38. Carlini P, Bria E, Giannarelli D, et al. New aromatase inhibitors as second-line endocrine therapy in postmenopausal patients with metastatic breast carcinoma: a pooled analysis of the randomized trials. Cancer 2005;104:1335-1342.

39. Mouridsen H, Gershanovich M, Sun Y, et al. Phase III study of letrozole versus tamoxifen as first-line therapy of advanced breast cancer in postmenopausal women: analysis of survival and update of efficacy from the International Letrozole Breast Cancer Group. J Clin Oncol 2003;21:21012109.

40. Mouridsen H, Gershanovich M, Sun Y, et al. Superior efficacy of letrozole versus tamoxifen as first-line therapy for postmenopausal women with advanced breast cancer: results of a phase III study of the International Letrozole Breast Cancer Group. J Clin Oncol 2001;19:2596-2606.

41. Nabholtz JM, Bonneterre J, Buzdar A, et al. Anastrozole (Arimidex) versus tamoxifen as first-line therapy for advanced breast cancer in postmenopausal women: survival analysis and updated safety results. Eur J Cancer 2003;39:1684-1689. 
42. Milla-Santos A, Milla L, Portella J, et al. Anastrozole versus tamoxifen as first-line therapy in postmenopausal patients with hormone-dependent advanced breast cancer: a prospective, randomized, phase III study. Am J Clin Oncol 2003;26:317-322.

43. Osborne CK, Pippen J, Jones SE, et al. Double-blind, randomized trial comparing the efficacy and tolerability of fulvestrant versus anastrozole in postmenopausal women with advanced breast cancer progressing on prior endocrine therapy: results of a North American trial. J Clin Oncol 2002;20:3386-3395.

44. Howell A, Pippen J, Elledge RM, et al. Fulvestrant versus anastrozole for the treatment of advanced breast carcinoma: a prospectively planned combined survival analysis of two multicenter trials. Cancer 2005;104:236239.

45. Howell A, Robertson JF, Quaresma Albano J, et al. Fulvestrant, formerly ICI 182,780 , is as effective as anastrozole in postmenopausal women with advanced breast cancer progressing after prior endocrine treatment. J Clin Oncol 2002;20:3396-3403

46. Howell A, Robertson JF, Abram P, et al. Comparison of fulvestrant versus tamoxifen for the treatment of advanced breast cancer in postmenopausal women previously untreated with endocrine therapy: a multinational, double-blind, randomized trial. J Clin Oncol 2004;22:1605-1613.

47. Robertson JF, Erikstein B, Osborne KC, et al. Pharmacokinetic profile of intramuscular fulvestrant in advanced breast cancer. Clin Pharmacokinet 2004:43:529-538.

48. Di Leo A, Jerusalem G, Petruzelka L, et al. Results of the CONFIRM phase III trial comparing fulvestrant $250 \mathrm{mg}$ with fulvestrant $500 \mathrm{mg}$ in postmenopausal women with estrogen receptor-positive advanced breast cancer. J Clin Oncol 2010;28:4594-4600.

49. Robertson JF, Lindemann JP, Llombart-Cussac A, et al. Fulvestrant 500 $\mathrm{mg}$ versus anastrozole $1 \mathrm{mg}$ for the first-line treatment of advanced breast cancer: follow-up analysis from the randomized 'FIRST' study. Breast Cancer Res Treat 2012;136:503-511.

50. Mehta RS, Barlow WE, Albain KS, et al. Combination anastrozole and fulvestrant in metastatic breast cancer. N Engl J Med 2012;367:435-444.

51. Bergh J, Jonsson PE, Lidbrink EK, et al. FACT: an open-label randomized phase III study of fulvestrant and anastrozole in combination compared with anastrozole alone as first-line therapy for patients with receptorpositive postmenopausal breast cancer. J Clin Oncol 2012;30:1919-1925.

52. Fry DW, Harvey PJ, Keller PR, et al. Specific inhibition of cyclindependent kinase 4/6 by PD 0332991 and associated antitumor activity in human tumor xenografts. Mol Cancer Ther 2004;3:1427-1438.

53. Gillett C, Fantl V, Smith R, et al. Amplification and overexpression of cyclin D1 in breast cancer detected by immunohistochemical staining. Cancer Res 1994;54:1812-1817.

54. Yu Q, Sicinska E, Geng Y, et al. Requirement for CDK4 kinase function in breast cancer. Cancer Cell 2006;9:23-32.

55. Finn RS, Dering J, Conklin D, et al. PD 0332991, a selective cyclin D kinase $4 / 6$ inhibitor, preferentially inhibits proliferation of luminal estrogen receptor-positive human breast cancer cell lines in vitro. Breast Cancer Res 2009;11:R77.

56. Finn RS, Crown JP, Lang I, et al. Final results of a randomized Phase II study of PD 0332991, a cyclin-dependent kinase (CDK)-4/6 inhibitor, in combination with letrozole vs letrozole alone for first-line treatment of ER+/HER2 - advanced breast cancer (PALOMA-1; TRIO-18). Presented at: AACR Annual Meeting 2014; April 5-9, 2014; San Diego, California.
57. Vallabhaneni S, Nair BC, Cortez V, et al. Significance of ER-Src axis in hormonal therapy resistance. Breast Cancer Res Treat 2011;130:377-385.

58. Paul D, Vukelja SJ, Holmes FA, et al. Letrozole plus dasatinib improves progression-free survival (PFS) in hormone receptor-positive, HER2negative postmenopausal metastatic breast cancer (MBC) patients receiving first-line aromatase inhibitor therapy [abstract]. Cancer Res 2013;73:Abstract S3-07

59. Chia S, Gradishar W, Mauriac L, et al. Double-blind, randomized placebo controlled trial of fulvestrant compared with exemestane after prior nonsteroidal aromatase inhibitor therapy in postmenopausal women with hormone receptor-positive, advanced breast cancer: results from EFECT. J Clin Oncol 2008;26:1664-1670.

60. Campbell RA, Bhat-Nakshatri P, Patel NM, et al. Phosphatidylinositol 3-kinase/AKT-mediated activation of estrogen receptor alpha: a new model for anti-estrogen resistance. The J Biol Chem 2001;276:9817-9824.

61. Simoncini T, Hafezi-Moghadam A, Brazil DP, et al. Interaction of oestrogen receptor with the regulatory subunit of phosphatidylinositol-3-OH kinase. Nature 2000;407:538-541.

62. Chang SB, Miron P, Miron A, Iglehart JD. Rapamycin inhibits proliferation of estrogen-receptor-positive breast cancer cells. J Surg Res 2007;138:3744.

63. Ghayad SE, Bieche I, Vendrell JA, et al. mTOR inhibition reverses acquired endocrine therapy resistance of breast cancer cells at the cell proliferation and gene-expression levels. Cancer Sci 2008;99:1992-2003.

64. Piccart M, Hortobagyi GN, Campone M, et al. Everolimus plus exemestane for hormone receptor-positive $(\mathrm{HR}+)$, human epidermal growth factor receptor-2-negative (HER2-) advanced breast cancer (BC): overall survival results from BOLERO-2. Ann Oncol 2014;25:2357-2362.

65. Paplomata E, Zelnak A, O'Regan R. Everolimus: side effect profile and management of toxicities in breast cancer. Breast Cancer Res Treat 2013;140:453-462.

66. Baselga J, Campone M, Piccart M, et al. Everolimus in postmenopausal hormone-receptor-positive advanced breast cancer. N Engl J Med 2012;366:520-529.

67. Bachelot T, Bourgier C, Cropet C, et al. Randomized phase II trial of everolimus in combination with tamoxifen in patients with hormone receptor-positive, human epidermal growth factor receptor 2-negative metastatic breast cancer with prior exposure to aromatase inhibitors: a GINECO study. J Clin Oncol 2012;30:2718-2724.

68. Massarweh S, Romond E, Black EP, et al. A phase II study of combined fulvestrant and everolimus in patients with metastatic estrogen recepto (ER)-positive breast cancer after aromatase inhibitor (AI) failure. Breast Cancer Res Treat 2014;143:325-332.

69. Sabnis GJ, Goloubeva O, Chumsri S, et al. Functional activation of the estrogen receptor-alpha and aromatase by the HDAC inhibitor entinostat sensitizes ER-negative tumors to letrozole. Cancer Res 2011;71:1893-1903.

70. Yardley DA, Ismail-Khan RR, Melichar B, et al. Randomized phase II, double-blind, placebo-controlled study of exemestane with or without entinostat in postmenopausal women with locally recurrent or metastatic estrogen receptor-positive breast cancer progressing on treatment with a nonsteroidal aromatase inhibitor. J Clin Oncol 2013;31:2128-2135.

71. Wolff AC, Lazar AA, Bondarenko I, et al. Randomized phase III placebocontrolled trial of letrozole plus oral temsirolimus as first-line endocrine therapy in postmenopausal women with locally advanced or metastatic breast cancer. J Clin Oncol 2013;31:195-202. 